Max-Planck-Institut für demografische Forschung

Max Planck Institute for Demographic Research

Konrad-Zuse-Strasse 1 - D-18057 Rostock · GERMANY

Tel +49 (0) 3812081 - 0; Fax +49 (0) 3812081 - 202;

http://www.demogr.mpg.de

MPIDR WORKING PAPER WP 2006-026

AUGUST 2006 (REVISED NOVEMBER 2007)

\title{
Stochastic forecast of the population of Poland, 2005 - 2050
}

\author{
Anna Matysiak (amatys@sgh.waw.pl) \\ Beata Nowok (b.nowok@cefmr.pan.pl) \\ The authors were students of the European Doctoral School of \\ Demography at the MPIDR.
}

This working paper has been approved for release by: Jutta Gampe (gampe@demogr.mpg.de) Head of the Office of Statistics and Information Services.

(C) Copyright is held by the authors.

Working papers of the Max Planck Institute for Demographic Research receive only limited review. Views or opinions expressed in working papers are attributable to the authors and do not necessarily reflect those of the Institute. 


\title{
STOCHASTIC FORECAST OF THE POPULATION OF POLAND, 2005 - 2050
}

\author{
Anna Matysiak $^{1 \mathrm{a}, 2}$, Beata Nowok $^{1 \mathrm{~b}, 3, *}$ \\ ${ }^{1}$ MPIDR fellow ${ }^{\mathrm{a}} /$ NIDI fellow ${ }^{\mathrm{b}}$, European Doctoral School of Demography, Max Planck Institute \\ for Demographic Research, Rostock \\ ${ }^{2}$ Warsaw School of Economics, Institute of Statistics and Demography, Warsaw; Gdansk \\ Institute for Market Economics, Warsaw \\ ${ }^{3}$ Central European Forum for Migration Research, Warsaw
}

\begin{abstract}
Forecasting the population of Poland is very challenging. Firstly, the country has been undergoing rapid demographic changes. In the 1990s, Poland experienced a fundamental shift from a communist regime to a democratic regime and entered the European Union in 2004. The political, economic, and social changes that accompanied the transformation had a profound influence on the demographic patterns in this country. International migration has been one of the first consequences of Poland's entry into the EU, and it is expected to increase in the future. Secondly, the availability of statistics for Poland on past trends is strongly limited. The resulting high uncertainty of future trends should be dealt with systematically, which is an essential part of the stochastic forecast. In this article, we present to the best of our knowledge a first stochastic forecast of the population of Poland. The forecast constitutes a valuable alternative to considering various scenarios that have been applied so far. The forecast results show that the Polish population will constantly decline during the next decades. There is a probability of $50 \%$ that in 2050 the population will number between 27 and 35 millions compared to 38.2 in 2004 . Besides, Poland will face significant ageing as indicated by a rising old-age dependency-ratio. In 45 years, there will be at least 63 persons aged 65+ per 100 persons aged 19-64, and this with a probability of $50 \%$. A description of the most important limitations to the official Polish demographic statistics and an analysis of past trends in fertility, mortality, and international migration are important by-products of this study.
\end{abstract}

Key words: stochastic forecast, Poland, predictive distributions, uncertainty

* The authors are listed in alphabetical order 


\section{Contents}

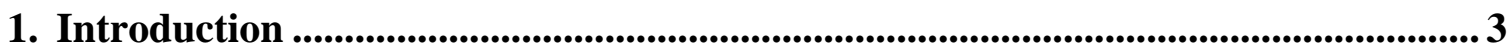

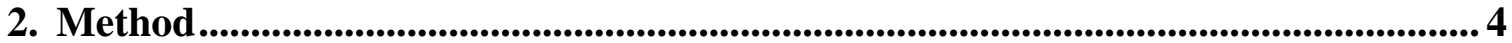

3. Forecast assumptions ...................................................................................................... 6

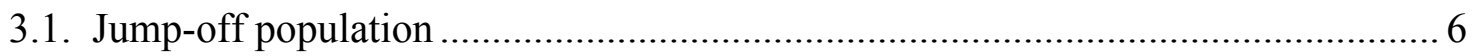

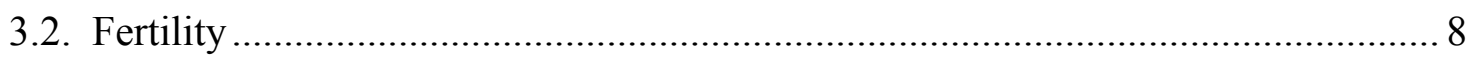

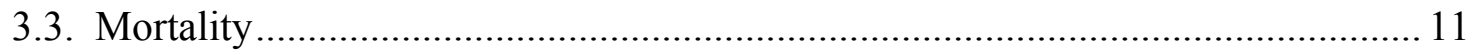

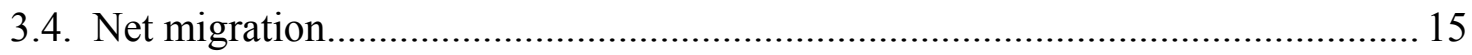

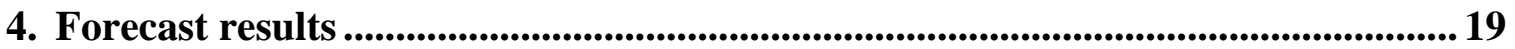

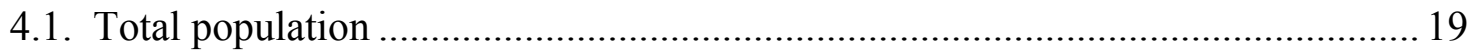

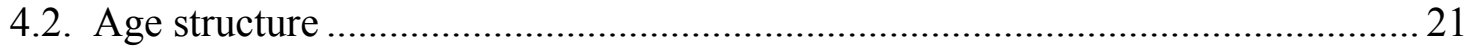

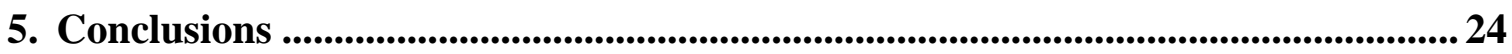

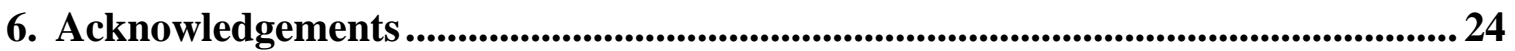

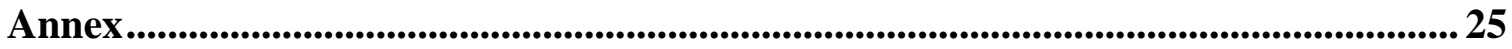

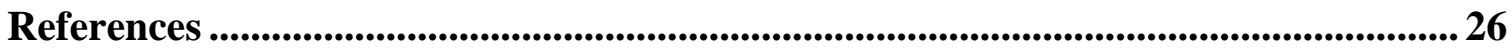




\section{Introduction}

Ever since the beginning of the 1990s, Poland has been experiencing rapid changes in its demographic patterns. In terms of family formation, these are the postponement or even abandonment of marriage and childbearing, the spread of alternative living arrangements and rising numbers of marriages ending in divorce. As a consequence, the Total Female Firstmarriage Rate dropped from 0.90 in 1989 to 0.57 in 2004 and the Total Fertility Rate fell from 2.03 to 1.23 . Mortality patterns in Poland have also undergone a significant change. Life expectancy has been rising since 1992 following two decades of very modest improvement and a temporary increase in mortality at the beginning of the 1990s. It increased by 4 years for women and nearly 4.5 years for men over the 1992-2004 period. The major improvement has been observed for infants. In 2004, the infant mortality rate was less than half of that in 1989. As regards international migration, the limited mobility of the past arising from political restrictions has come to an end and today migration from and to Poland is contributing significantly to the volume of migratory flows.

The process of demographic change in Poland has surely not ended yet. Although demographers have some expectations about the direction of future population developments in this country, a lot still remains uncertain. The uncertainty is growing owing to ongoing economic transformation in Poland, its entry into the EU, and the consequences of opening the national economy to highly competitive global markets. The ageing of Poland's population is an additional challenge. This process has already started and cannot be avoided. The higher percentage of the elderly will result in greater burdens on the working-age population in terms of financial support and care. Consequently, population ageing will affect the state of the country's public finances and its social security system. The direction of future demographic developments in Poland may depend significantly on whether or not the system undergoes the necessary reforms and the extent to which the state adjusts to the ongoing changes. The reforms need to be carefully planned, entailing detailed calculations of their costs and benefits. Qualitative experts' descriptions of the expected future do not suffice. Instead, a reliable population forecast is needed.

Since the beginning of the 1990s, several forecasts of the Polish population have been prepared. The most recent are a forecast of the Central Statistical Office (hereafter referred to as the CSO) for the years 2003-2030 (Bolesławski, 2004), of the United Nations for the years 2005-2050 (UN, 2004) and of Eurostat for the years 2005-2050 (EUROPOP2004). Each of them has three scenarios, of which one is perceived to be the most likely one and the other two to show the magnitude of divergence from the most likely path if some of the fertility, mortality, or international migration parameters are changed. Thus, alternative variants are developed to capture the uncertainty about the future developments in this country. The problem with this 
approach, however, is that no probability is attached to the scenarios. Nevertheless, for planning purposes it is crucial to know whether the given projection variant will be reached with a probability of $30 \%, 60 \%$ or $90 \%$ (Keilman and Pham, 2004).

We deal with this problem by implementing a stochastic approach. As far as we know, this will be the first time that a stochastic forecast for population of Poland is produced. Uncertainty about the future is taken into account by expressing assumptions on fertility, mortality, and migration in terms of their predictive probability distributions. This means that contrary to deterministic forecasts, we attach certain probabilities to certain scenarios. Random values from the assumed distributions for fertility, mortality, and migration are generated to produce a predictive probability distribution of population. The forecast results are presented in the form of median and prediction intervals. The forecast covers the 2005-2050 period.

The paper consists of three major sections. We begin with a brief description of the method. The second section presents the concept of the jump-off population as well as forecast assumptions on fertility, mortality, and migration. Each sub-section begins with a description of the data sources available. The presentation of the forecast assumptions on vital events is accompanied by a description of their past trends and assumptions on uncertainty. Finally, our assumptions are compared to those of the $\mathrm{CSO}, \mathrm{UN}$, and Eurostat. The third section of the study presents the results of our forecast. Similarly to the assumptions, they are compared with the results obtained in other demographic forecasts for Poland.

\section{Method}

Similarly to other conventional population forecasts, the probabilistic forecast is based on the cohort-component model. The difference, however, is that instead of formulating alternative low and high scenarios, probabilistic forecasting requires the specification of prediction intervals for future age-specific vital rates and migration flows. The randomly selected rates and flows from these intervals then are used to derive the predictive distribution for the population numbers. Technically, this is achieved by running the cohort-component model several thousand of times.

In the literature, there are three methods of producing the predictive distributions for fertility, mortality, and migration: time-series extrapolation, expert judgement, and an analysis of past forecast errors (Alho and Spencer, 2005, p. 238-256; Keilman et.al., 2002). In practice, a combination of at least two of these methods is used to produce the predictive distributions. The first method is based on statistical models fitted to historical data. However, it tends to give excessively wide predictive distributions due to difficulties in explaining variation in past trends. 
Therefore, expert judgment is used to correct the resulting prediction intervals. The last method is based on the extrapolation of errors made in past forecasts. Its drawback is that for some countries the forecasts dating far back into the past either are not well documented, not available, or simply non-existent.

In order to produce a stochastic forecast for the population of Poland, we proceed as follows. We formulate arbitrary point forecasts for age-specific fertility rates, age-specific mortality rates, and age-specific net migration flows. Unfortunately, an extrapolation of past trends and past forecast errors to produce the prediction intervals for Poland is not possible as long time-series and population forecasts dating far back into the past are not available. Therefore, we use an empirical specification of the error structure estimated by Alho and Spencer (2005) for selected European countries and, when necessary, these estimates are further adjusted by expert judgments on the Polish conditions. The so-called scaled model for error (Alho and Spencer, 2005 ) is used to approximate error structures. For each component of demographic change, uncertainty is assumed to increase with the forecast year. The uncertainty of age-specific mortality and fertility rates is treated in relative (logarithmic) terms. The scales of the model for errors are constant over time. For fertility, the error increments are assumed to be uncorrelated. Therefore, the model can be interpreted as a random walk. For mortality, the autocorrelation of error increments is 0.05 and the model can be interpreted as a random walk with a random drift. The uncertainty of net migration is represented in absolute terms by using information on gross migration. Dependence on age is deterministic and given by a fixed distribution over age. The constant autocorrelation of error increments is assumed to be 0.3. Autoregressive (AR(1)) correlations for the error increments across ages (fertility and mortality) and sexes (mortality and net migration) are assumed. The variability of fertility, mortality, and migration is treated as independent of each other.

Thus, the future path of the vital rates and international migration are specified by point forecasts and stochastic error terms. Using a cohort component model, 3,000 simulations are run in order to propagate uncertainty from fertility, mortality, and net migration to the future population number. For our computations, we use the computer program PEP (Program for Error Propagation) developed by Alho (n.d.) at the University of Joensuu. 


\section{Forecast assumptions}

\subsection{Jump-off population}

The jump-off population of the forecast is the Polish population as of 31 December 2004, by sex and single years of age $(0,1,2, \ldots, 100+)$. According to the official estimates, based on the results of the last census (20 May 2002) and based on annual vital registration data, the total population of Poland at that time amounted to 38.174 million.

The official annual population statistics in Poland suffer from serious conceptual drawbacks, however. At the national level, they capture the population permanently resident, i.e. persons registered for permanent stay in Poland. The problem with this is that there is a second type of residence, namely a temporary one. This residence should be recorded in the population register for each stay outside the permanent place of residence (in the country or abroad) exceeding two months. Thus, a person may have a temporary place of residence at the same time as having a permanent place of residence. Besides, there is no upper limit to the former. As a result, a number of people who are temporarily abroad in theory may have been living there already for a few years and they may treat the destination country as their new place of usual residence. These "emigrants" are included in the population of Poland unless they formally give up their permanent place of residence. At the same time, persons with a permanent place of residence abroad who live in Poland just temporarily are not included in the official population statistics. Foreigners who want to settle in Poland are treated as inhabitants of Poland after they have received a permanent residence permit, i.e. after having lived there without interruption for at least three years.

Thus, the concept used in the official statistics corresponds neither to the de jure nor to the de facto population ${ }^{1}$. Currently, Poland is an emigration country. Out-migration is usually underregistered, thus the figure for the Polish population is larger than it would be according to the two internationally recognised concepts of population mentioned above. Another misleading factor is that the CSO considers the permanently resident population to be the de jure population whilst at the national level it is equal to the population regarded by the CSO as de facto population (at the sub-national level, persons with both a permanent and temporary place of residence are counted as de facto residents at their temporary place of residence).

The usually resident population was estimated for the first time in the 2002 Census and it has been the only one estimation so far. The usual residents of Poland were distinguished by applying

\footnotetext{
${ }^{1}$ A de facto population consists of all individuals present in the area regardless of their usual place of residence and a de jure population covers all persons usually resident, which are present or absent in the area. For details on the concept of a usually resident population, see United Nations and Eurostat (1998, 11-13).
} 
the criterion that the individuals concerned stayed in Poland for at least 12 months. This means that persons who stayed in Poland for at least 12 months were included in the resident population and persons who were staying abroad for at least 12 months were excluded from the resident population. Therefore, the last census results allow for a comparison to be made between the permanent and the usually resident population as of 20 May 2002. The discrepancy between the two population groups is about 610,000 persons (1.6\% of the total permanent population of Poland). There were 22,700 persons who lived in Poland on a temporary basis for at least 12 months and 626,000 permanent residents of Poland who were absent from the country for at least 12 months. As the information on emigrants can not be collected from the emigrants themselves, the reliability of the latter figure is questionable, e.g., families who left the country are not covered. Besides, the figures for permanent and usual residents include persons who could not have been enumerated by fieldwork for various reasons unfortunately unspecified and the basic information about them was obtained from the population register. The CSO (2003) estimated that about 730,000 permanent residents were enumerated that way and the majority of them were also included in the usually resident population. The above comparison leads us to conclude that even if we ignore a possible underestimation of temporary emigration, there still is a difference between the usually and the permanently resident population.

Note that there is a strict connection between the population concept and the reliability of the vital rates, especially fertility rates. An application of the permanent residence concept causes a nominator-denominator bias, i.e. children born abroad to permanent residents of Poland are usually not covered by figures on birth, but their mothers are included in the population at risk.

Although the definition of permanent population has received criticism, we are forced to use data based on this concept. Data availability on the usually resident population is highly limited. The total number of the usually resident population on 20 May 2002 is not disaggregated by age and the appropriate migration data are missing. Additionally, note that the very change of the population concept from permanent, used by the CSO when producing annual population statistics, to usually resident, would not solve the existing data problem. It must be accompanied by a change in people's attitudes towards registration rules; these are usually not adhered to, in particular by people leaving the country.

Unfortunately, even if we used statistics on the permanent population instead of statistics on the usually resident population, uncertainty surrounding the figures still remains. The population number on 31 December 2000 adjusted after the 2002 Census suggests that 390,000 permanent residents were not included compared with the data calculated by using the balancing equation of population change. The difference is tied up with undocumented migration. This may give raise to doubts on the reliability of the figures of 31 December 2004, although the bias should be lower as relatively short time elapsed since the last census. In addition, since the results of the post- 
enumeration survey are not easily accessible, we are not able to assess the quality of the census itself. In this situation, the uncertainty of the jump-off population should be taken into account in the forecast. Unfortunately, this can not be done since the current version of PEP does not allow for this source of uncertainty.

\subsection{Fertility}

Fertility assumptions for Poland are based on the observation of past trends in age-specific fertility rates. Moreover, as Polish couples have been changing their fertility behaviour only since recently (implying high uncertainty as to any likely recuperation effect at older childbearing ages), we also analyse fertility trends in other European countries. We pay special attention to Spain and Italy. Similarly to Poland, the two countries have a strong Catholic tradition, a family orientation that is high, and family and labour market regulations that are considered to create serious constraints to the reconciliation between work and family (e.g. Muszyńska, 2005; Kotowska et.al., 2005). Fertility has reached lowest low levels in the two Mediterranean countries as well as in Poland (i.e. the Total Fertility Rate is below 1.35), but the process of decline in the former countries began much earlier than in the latter. Furthermore, in recent years a slight increase in the Total Fertility Rates of the aforementioned Mediterranean countries has been observed, and this observation may be the result of fertility postponement in the past.

In order to formulate fertility assumptions, we collected the time series of age-specific fertility rates for Poland, Italy, and Spain. We had access to data on the Mediterranean countries by single age, covering the period of 1971-2000 (Spain) and 1950-2000 (Italy). The data stem from the Eurostat online database. Data collection for Poland was more complicated, requiring that we use different data sources and some interpolation procedures. A detailed description of the data sources used is presented in Table 1 in the Annex.

Before the economic transformation, Poland witnessed relatively high fertility by European standards. The Total Fertility Rate declined from 3 children per woman in the 1950s and oscillated around 2.2-2.3 in the 1970s and 1980s. The highest intensity of births was observed in the age group 20-24 and the mean age at childbirth was nearly 26 years at the end of the 1980s. After the fall of the communist regime, Poland experienced a major change in fertility patterns, reflected mainly in a drastic drop in fertility rates over the first six years of economic transformation and a further decline accompanied by a shift in birth intensities toward higher ages since the mid 1990s. As a result of these changes, the Total Fertility Rate decreased to 1.227 in 2004 (with the lowest value being 1.223 in 2003). In the meantime, the mean age at childbirth rose by nearly two years, to 27.9. The intensity of fertility decline in urban areas was similar to 
that in rural areas. Starting from the lower level, the Total Fertility Rate in the former dropped to 1.107 in 2003 . Only in 2004 did it increase for the first time since 1989, to 1.124. This may indicate a slight reversal of the negative trend in urban areas (implying a recuperation effect at older ages). Such a phenomenon has not been observed in rural areas so far; here the Total Fertility Rate is still continuously declining (1.421 in 2004).

A similar pattern of fertility decline was observed in the late 1970s and 1980s in Spain and Italy. Here, the Total Fertility Rate dropped from replacement level to around 1.3 within about 10 years. The downward trend continued for the next 8-10 years, at a lower intensity however, and resulting in a Total Fertility Rate of 1.18 in Italy (1995) and of 1.15 in Spain (1998). Since then, a slightly rising tendency has been observed and in 2004 the countries reached a TFR of 1.33 and 1.32, respectively. This process was continuously accompanied by a shift in birth intensities toward higher ages and may indicate a recuperation effect. Although the process has probably not ended yet, its magnitude seems to be weak.

Based on past trends for Poland, Spain, and Italy, we assume that the negative trend in Poland will slightly reverse. The effect will be slower in the first two years of the forecast when we expect a minor rise in urban fertility but a continuing decline in rural fertility. After 2006, the rise in Total Fertility Rate will accelerate as a consequence of childbearing recuperation at older ages. Nevertheless, we do not expect this increase to be strong. In our opinion, fertility will remain low due to serious constraints to the reconciliation between work and family, an existing lack of political will to introduce reforms to family policy and to integrate these reforms with other social and employment policies as well as rising competition in the labour market. Hence, our point forecast for the Total Fertility Rate is 1.35 in 2030 and beyond. This development will be accompanied by a further postponement of births. Therefore, we assume that the age distribution of fertility will resemble that of Spain or Italy today. This implies that the point forecast for the mean age at birth will rise to 30.5 in 2030 and remain constant afterwards. Technically, this is achieved by lowering the fertility rates in ages below 27.9 and raising the rates in ages above 27.9, using an exponential transformation (Alho, 1998). The result is presented in Figure 1. 
Figure 1 Age-specific fertility rates, past and forecasted values, 1975-2050

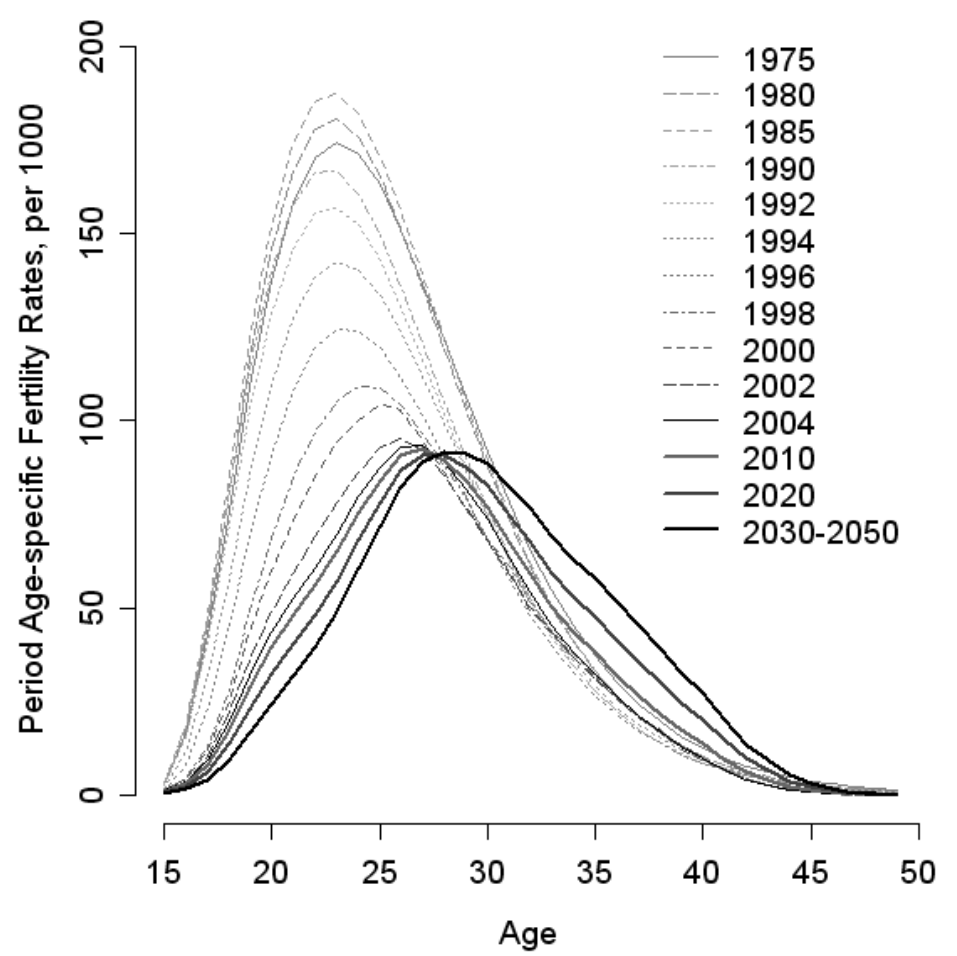

The uncertainty of our assumptions on fertility rates is described by a probability distribution around our point forecast. The key issue at this point is the calculation of the standard deviation. We do not have access to long time-series and past forecasts dating far back into the past for Poland that would allow for its computation. For this reason, we use the estimates of relative errors in naive fertility forecasts calculated by Alho and Spencer (2005) for six European countries (the Netherlands, Denmark, Norway, Finland, Iceland, and Sweden) over the time span beginning between 1751 and 1900 and ending in 2000. This is a period of high volatility in fertility patterns in the countries studied. Using these relative errors, we assume that fertility in Poland will be equally variable. Given the long forecast period and the magnitude of change in fertility patterns over the last 15 years, this assumption seems to be plausible. This yields $80 \%$ prediction intervals of $[0.99,1.82]$ in 2030 and $[0.90,2.01]$ in 2050. 
Figure 2 Total Fertility Rate, past and forecasted values

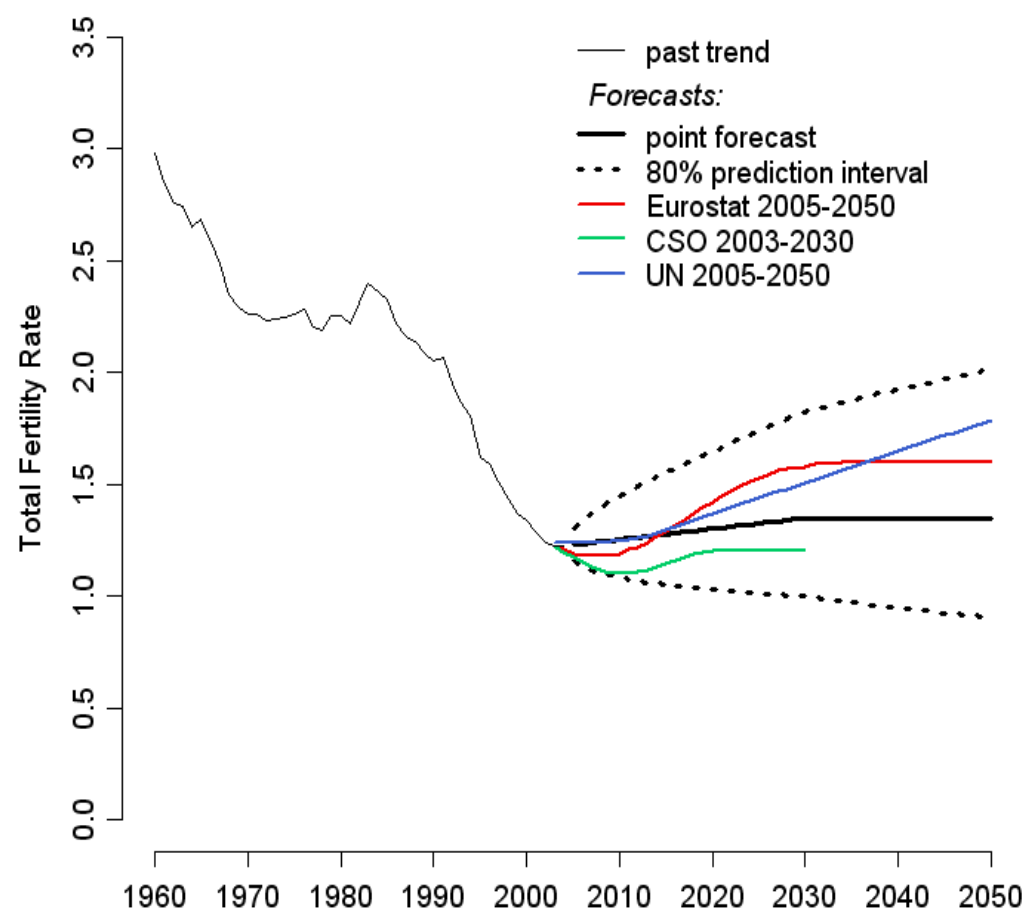

A comparison of our point forecast for the TFR with the assumptions of other available forecasts for the Polish population shows that only the CSO assumes the population to display lower fertility levels. The base scenario of the last CSO forecast from 2003 assumes a further decline in the TFR to 1.1 in 2010 , followed by a rise to 1.2 in 2020 . This is also the level at which the TFR is supposed to remain constant until 2030 according to the CSO. The other two forecasts, one by the UN and the other one by Eurostat, are much more optimistic. Whereas Eurostat claims that there will be a continuous drop in the TFR to 1.18 in the years 2006-2009 followed by a rise to 1.64 in 2034 with no change afterwards, the UN assumes a linear increase to nearly 1.8 in 2050 from the beginning of the forecast period. Nevertheless, although our point forecast differs from those of the CSO, UN, and Eurostat, our 80\% prediction intervals cover the whole range of predicted values and even allow for the possibility that fertility will fall further (Figure 2).

\subsection{Mortality}

Similarly to fertility, mortality assumptions were based mainly on the observation of past trends. Detailed information on data sources and procedures used for calculating the required indicators is provided in Table 2 in the Annex. As a final outcome, we had at our disposal life age-specific mortality rates by sex for the 1950-2004 period. This indicator for ages up to 100, however, was available only for the 1971-2004 period (earlier data covered ages 0-80). Moreover, the data on 
old-age mortality turned out to be relatively volatile for both women and men, irrespective of the data source used. For this reason, we replaced the old-age mortality rates by a linear extrapolation of the logarithm of mortality rates for ages 30-79 for men and 71-79 for women ${ }^{2}$.

In the post-war period, Poland experienced relatively strong improvement in mortality. Life expectancy at birth in the 1950s rose from 56.1 to 64.9 for men and from 61.7 to 70.6 for women. A rising tendency, although much weaker, was also observed in the 1960s. In the next two decades, the improvement came to a halt. While for women, life expectancy at birth increased by less than 2 years during this period, there was nearly no change for men. What is more, one even observed some temporary ups and downs in male life expectancy. These developments contributed to a further increase in the gender gap in mortality that was already widening in the 1960s (the gap in life expectancy grew from 5.6 years in 1960 to 8.7 in 1989). The fall of the communist regime is marked by a sudden rise in mortality for all age groups. This phenomenon was, however, only a temporary one and since 1992 a continuous fall in mortality has been observed. As a result, female life expectancy increased by nearly 4 years (to 79.2 in 2004) and that for men rose by 4.5 years (to 70.7 in 2004) compared to 1991. The improvement in mortality was strongest for infants. The infant mortality rate in 2004 was less than half of that in 1989.

Given the trends described above, we expect that the improvement in mortality observed since 1992 will continue in the future. With time, however, the rates of decline will weaken, converging to those observed in the most developed countries of Europe. The slowdown in mortality improvement can be explained by the fact that the sudden drop in mortality during the 1992-2004 period was most probably the result of a rapid increase in living standards and the spread of a healthy life style. This trend will continue for some time as Poland's level of economic development will converge to the EU average. In our opinion there is, however, no reason to believe that in the long term life expectancy in Poland will increase faster than it has been observed so far in the most developed countries in Europe.

The initial annual rates of decline in mortality were estimated from the observed mortality rates for all single years of age for the 1992-2004 period. The rates of decline obtained in that way have some problems, however. First, they varied across single age. Second, the rates of decline for ages 60-90 were much higher for women than they were for men. While the first problem was easily solved by applying some smoothing procedures, the second required more consideration. Generally, leaving the rates on the level obtained after smoothing would result in a further widening of the gender gap in mortality. Since in the majority of the EU-15 countries this gap is already much smaller than it is in Poland, it is very unlikely that it will continue to grow. For this reason, we lowered the difference in the rates of decline by increasing the male rates by one third

\footnotetext{
${ }^{2}$ While the logarithm of male mortality rates shows a linear trend for ages $30-79$, this applies to women only for the last ten ages.
} 
of the difference and by lowering the female rates by half of the difference. Next, we assumed that the obtained rates of decline will decrease linearly until 2030 to reach the average rates of decline calculated for Austria, Denmark, Finland, France, Germany, Italy, the Netherlands, Norway, Sweden, Switzerland, and the United Kingdom for the last 30 years (UPE, 2004). The resulting mortality rates are presented in Figures 3 and 4.
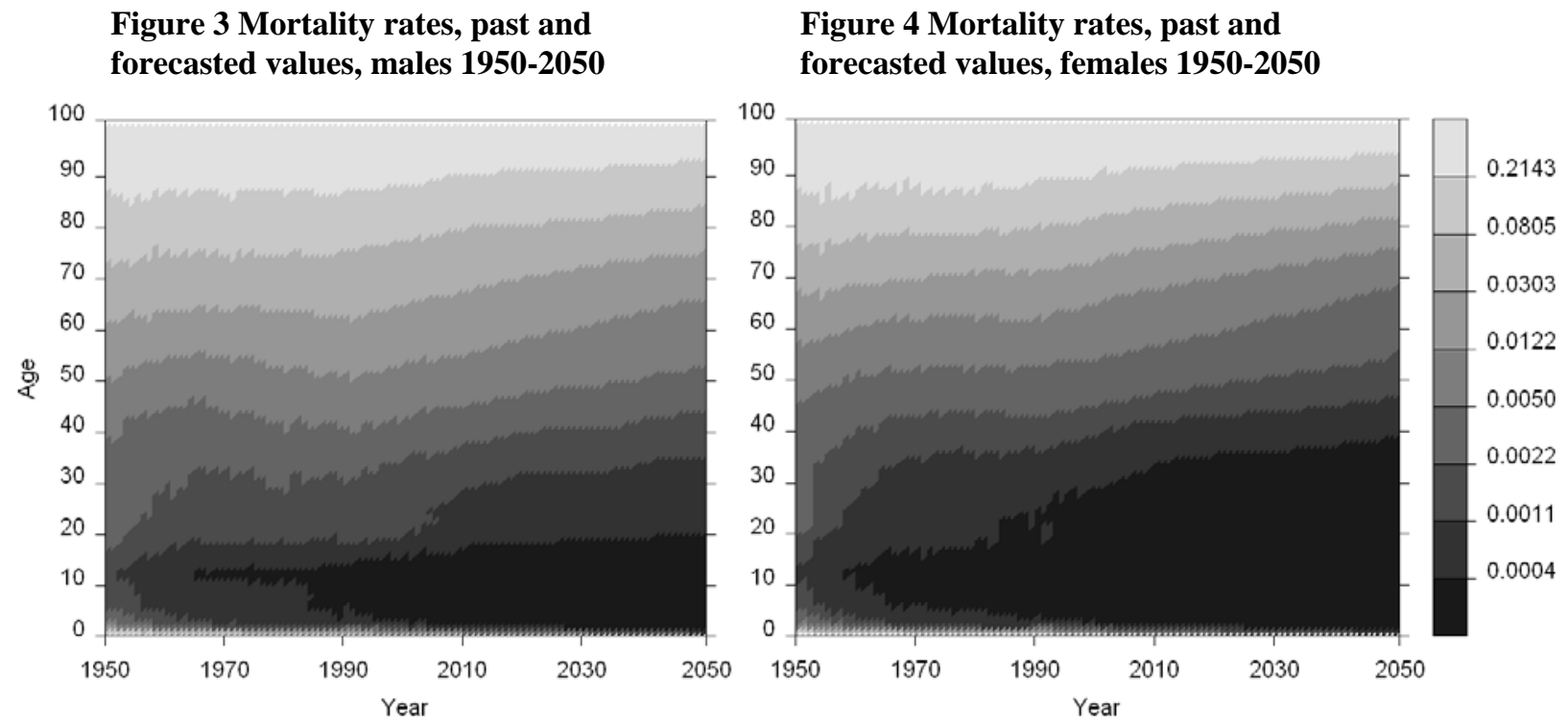

Similarly to fertility, our assumptions on mortality are uncertain. On the one hand, it seems quite plausible that the recent improvements in mortality will continue. This should happen as a consequence of technological progress in medicine, further prevention of diseases, and the spread of a healthier lifestyle. This effect should be particularly strong in Poland as it still has a lot to catch up with EU-15. On the other hand, whether mortality declines or not highly depends on the economic development of the country and the state of public health care. The latter currently is and may continue to remain in poor conditions if major reforms are not undertaken. This issue will become more urgent and more difficult to address in view of the ongoing process of population ageing. Moreover, we do not have an answer yet to the question whether or not there are limits to rising life expectancy, an issue that is subject to current debate (see Oeppen and Vaupel, 2002; Olshansky et. al., 1990; Vaupel, 2005). This uncertainty is described by prediction intervals around our point forecast. Here too, we do neither have access to long time series nor to a large deal of long-term forecasts that would allow us to calculate the relative forecast errors. Therefore, we use the estimates by Alho and Spencer (2005), who compared mortality rates in nine European countries (Austria, Denmark, France, Italy, the Netherlands, Norway, Sweden, Switzerland, and the United Kingdom) with a baseline forecast, assuming decline in mortality by the observations made in the past 15 years. Their period of analysis covered a time span ending in 2000 and starting at various dates, with the earliest being 1841 for the UK. Although the mortality patterns largely changed in these countries at that time, for the reasons given above we 
have no grounds to claim that mortality developments in Poland will be less variable in the future than they were in the countries analysed by Alho and Spencer (2005). Hence, our choice of relative error estimates seems to be plausible. The magnitude of uncertainty as to the future mortality patterns is presented in form of $80 \%$ prediction intervals around the point forecast of the life expectancy derived from our assumptions on age-specific mortality rates. For men, this interval will be [73.6, 78.2] in 2030 and [75.8, 82.7] in 2050; for women it will be [82.0, 85.6] and [84.0, 89.3] (see Figures 5 and 6). In terms of the point forecast, this implies a rise in male life expectancy by 5.2 years until 2030 compared to $\mathrm{e}_{0}$ in 2004 and a climb by further 3.3 years until 2050. The improvements will be slightly lower for women: the point forecast increases by 4.5 years by 2030 and another 3 years by 2050 . This will contribute to a slight narrowing in the gender gap in life expectancy by 1.3 years.

Figure 5 Life expectancy at birth, past and forecasted values, males 1950-2050

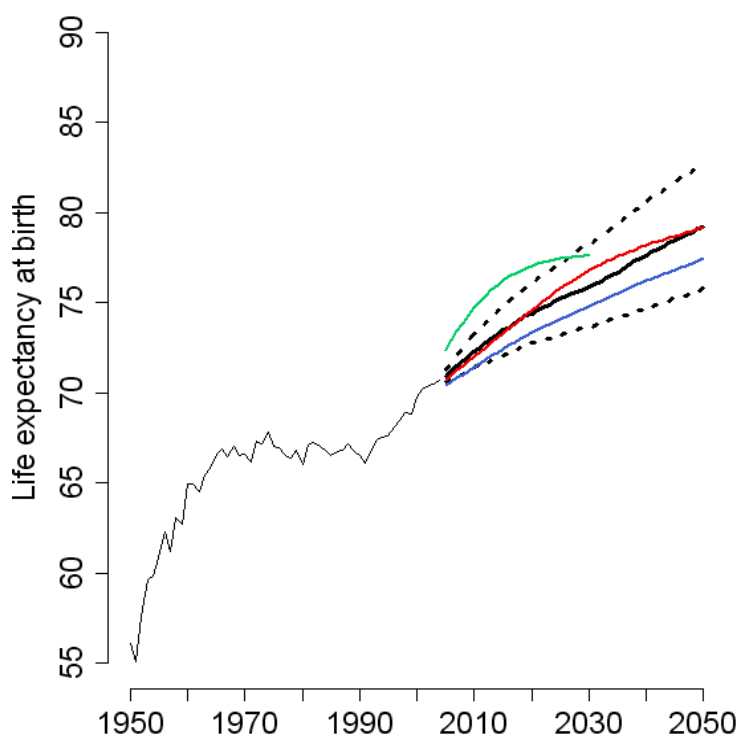

Figure 6 Life expectancy at birth, past and forecasted values, females 1950-2050

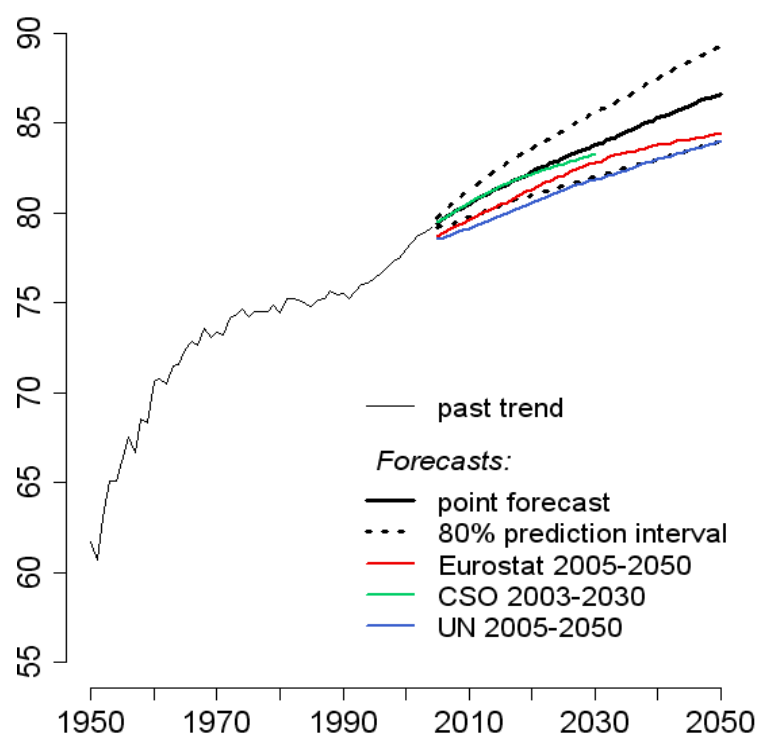

A comparison of our assumptions on life expectancy with the assumptions of other available forecasts shows that our prediction intervals for men generally cover the most likely scenarios predicted by the UN and Eurostat, with the latter being closest to our point forecast. The CSO predicts a much stronger rise in male life expectancy in the first decade, but thenafter the growth slows down and around 2030 the assumed $\mathrm{e}_{0}$ reaches the upper limit of our prediction interval. Contrary to our assumptions on male life expectancy, the assumptions on female life expectancy are more optimistic than those made by the UN and Eurostat. The values predicted by these institutions, particularly the $\mathrm{UN}$, are covered by the lowest parts of our $80 \%$ prediction intervals. The CSO forecast on female life expectancy is closest to our point forecast. Although we reduced the rates of decline in female mortality and increased the rates of decline in male mortality, the 
resulting gender gap in life expectancy in our point forecast is higher than it was assumed in other forecasts.

\subsection{Net migration}

International migration is a component of population change that is the most difficult to forecast in general and in Poland in particular. Firstly, the Polish statistics on international migration flows are of very poor quality (Nowok, 2005). Secondly, Poland's entry into the EU makes migration strongly dependent on political decisions, such as the timing of lifting restrictions on the free movement of labour for the citizens of the new 8 Member States by the old EU-15, and the future economic development of Poland.

Official Polish statistics on international migration and emigration flows cover lifetime migration only. They are produced on the basis of registration and deregistration forms that are filled out in the municipality when reporting a change in the place of permanent residence. Usually, however, people do not report their departure abroad. Thus, emigration is not covered in full and this is reflected in the population number obtained from the census count. The underestimation of Polish migration data is also evident when compared to the statistics reported by the EU countries that have a migration exchange with Poland (hereinafter referred to as partner countries) (Kupiszewska and Nowok, 2005). However, note that these discrepancies largely result from differences in the definition of migration and migrants.

The current study is based on official statistics on net migration (immigration minus emigration). These statistics have been corrected by using a post-census adjustment of the population number and statistics produced by the main EU destination countries. The net migration figures, which are calculated as a difference between immigration and emigration, are equal to the net migration figures obtained as residual values of annual population change and natural increase for all years except 2000. The post-census adjustment was applied to the total population number on 31 December 2000. Provided that the census and registration figures are accurate, the adjustment difference covers net migration accrued over the whole intercensal period. We therefore distributed it among the years 1989-2000. The distribution was carried out on the basis of the average share of net migration in a given year in a cumulative net migration for the whole period. Net migration was calculated for migration exchange with Germany, the Netherlands, and Sweden, using the statistics reported by these countries. Even if the migration exchange with Germany is much higher than with the Netherlands and Sweden (the other two most important partner countries for which data are available), we did not rely on the German data only, because they cover all stays exceeding one week. This is short a stay to qualify a movement as migration. 
The distribution reflects the undocumented migration wave that took place during the first years following the transformation of the political system in Poland in 1989. Besides, note that the cumulative official net migration figure for the 1989-2000 period $(192,000)$ was less than half of the value of our post-census correction $(390,000)$. The average relative increase of net migration due to applied adjustments for the period 1995-2000 was used to correct the values of net migration for 2001-2004, calculated from the Polish official statistics on immigration and emigration. An additional correction was applied to the figure for 2004, the first year of Poland's membership in the EU (since 1 May 2004). According to the European main partner countries for which data were available (Germany, the Netherlands, Spain and Sweden), their positive migration balance with Poland on average doubled. Polish data showed an opposite trend, i.e. an increase in net migration compared to the previous year. The adjustment was introduced on the basis of the assumption that the bias of net migration data is connected mainly to the emigration component and thereby to the migration exchange with the destination countries of migrants from Poland.

The age pattern of both immigration and emigration obtained from the Polish statistics (2004, by single age, and 1999-2003 by 5 year age groups, interpolated by the Karup-King method) was unrealistic, and this additionally lowers the quality of the Polish data on international migration flows. Therefore, the initial age pattern of net migration was derived on the basis of data on immigration and emigration by the country of previous and next residence respectively produced by the main partner countries. The average of the age pattern of the migration exchange with the following countries in 2004 was used: Germany, Austria, the Netherlands, Italy, Spain, and Sweden. However, starting from age 80 , zero migration was assumed.

The low reliability of the statistics on international migration flows available for Poland hinders an analysis of historical trends. However, some general and characteristic features can be distinguished. During the pre-transition period (1950-1988), the population movement was constrained by political factors and responded to fluctuating restrictions. Migration reached a significant level only in some exceptional cases and only specific categories of migrants were involved, e.g. ethnic Germans and Polish Jews. The sudden increase in migration outflow took place after the collapse of the communist regime in 1989, when people started to move abroad freely. Following a period of high intensity of migratory movements, net migration was rather stable and oscillated between $-14,000$ and $-20,000$ (-28,000 and $-46,000$ after our correction), with the minimum level reached in 2000, most probably connected to the deterioration of the economic situation in Poland.

Owing to Poland's entry into the EU, the future trend of international migration depends largely on the political decisions made by individual EU-15 Member States regarding the free movement of labour. The turning points in that respect are defined by the transitional arrangements set out in 
the Treaty of Accession of 2003. The transitional period (1 May 2004 - 30 April 2011) is divided into three distinct phases, according to the "2-plus 3-plus 2" formula. The first 2-year period ended on 30 April 2006. During this period, the three countries that opened their labour markets, namely Ireland, Sweden, and the United Kingdom, recorded an increase in immigration from the new Member States. On 1 May 2006, four additional countries ended the restrictions: Finland, Greece, Portugal, and Spain. The next verifications of the restrictions will take place in April 2009. All countries are obliged to end all constraints by 2011. The German government has already announced that it wants to prevent the uncontrolled inflow of cheap labour, in particular from Poland and the Czech Republic, for as long as possible. A similar decision was taken by Austria. For the other countries we have to make arbitrary assumptions on the date of opening their labour markets, based on the prevailing attitudes to foreign labour in these states. Thus, we assume that in 2009 all other countries except France will abandon the transition period. Besides, we assume that the removal of restrictions will result in a temporary increase in out-migration, in particular when Germany, currently the main destination country of Polish emigrants, opens its labour market. In general, we are of the opinion that Poland will follow the footsteps of Portugal and Ireland following their entry into the EU. This analogy is build on the basis of similarities in terms of an economic gap between the new Member State and the "old" EU. Therefore, net migration in Poland will first drop due to the dominating outflow to more affluent countries that have opened their labour markets. A minimum level of 88,500 will be reached in 2011 and 2012, i.e. in the years directly following the transition period for the free movement of workers. At the same time, the gradual improvement in the economic situation and the increasing relative attractiveness of Poland will result in an inflow of migrants, especially from the former Soviet Union countries. The immigration flow will then take precedence and in the long run Poland will become an immigration country. We assume that this will happen around 2025. In 2050, a level of 30,000 net migrants will be reached.

The assumed convergence of net migration to the EU pattern refers also to the age structure of net migrants. The initial age pattern will change linearly to adjust to the average EU pattern estimated in the UPE project, based on data from Austria, Belgium, Denmark, Iceland, Netherlands, Norway, Sweden, and Switzerland (UPE, 2004). This age pattern, reached in 2030, will remain constant for the rest of the forecast period. The number of net migrants by age is presented in Figure 7 for males and in Figure 8 for females. The sex structure is kept constant over the whole forecast period at the average level of the years 2000-2004 (the calculations are based on the Polish registration statistics). The share of males and females are $51 \%$ and $49 \%$ respectively. 
Figure 7 Net migrants by age, males

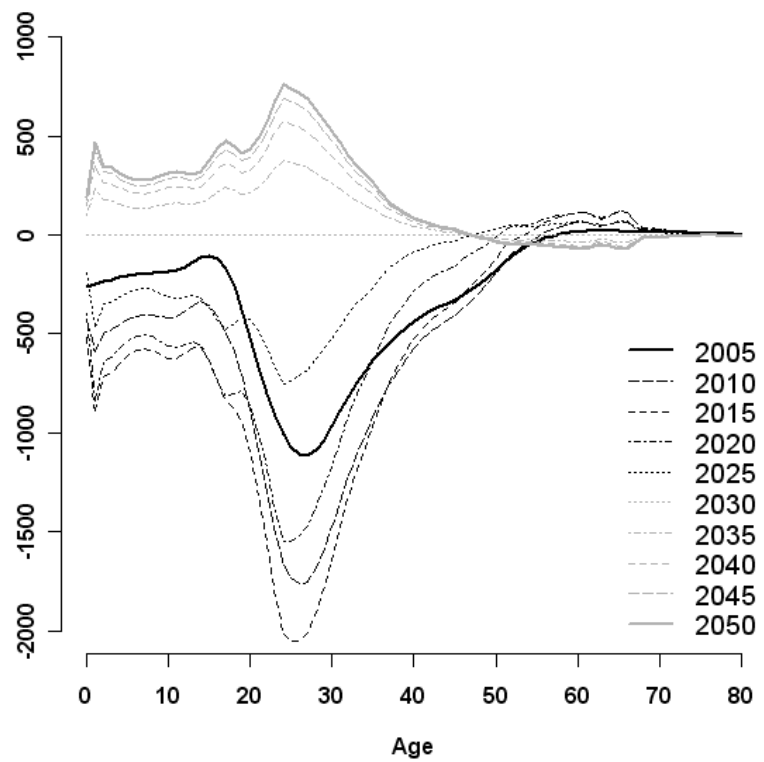

Figure 8 Net migrants by age, females

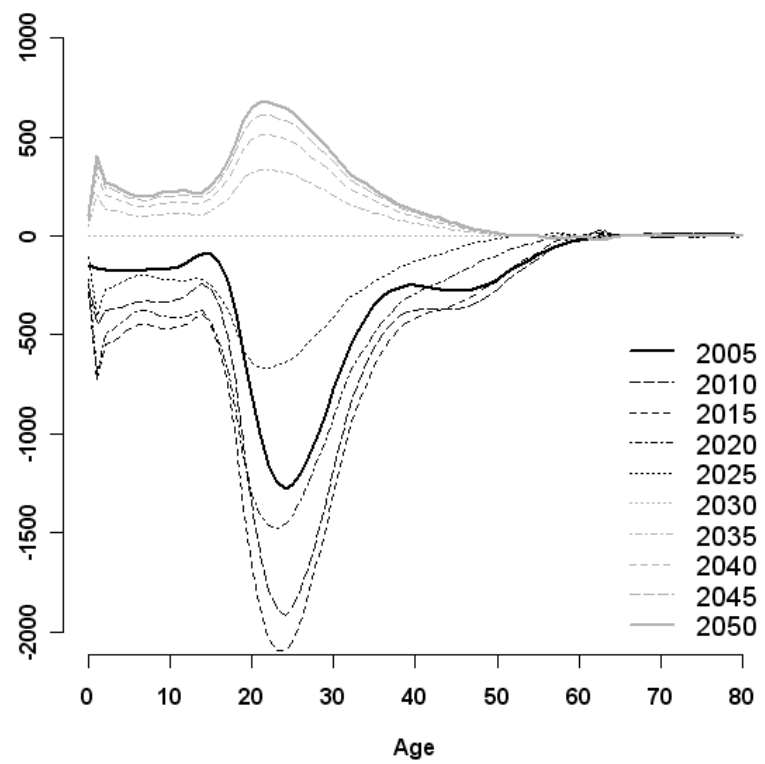

All of our assumptions are based on a judgmental view. Therefore, the uncertainty surrounding future net migration in Poland is of great importance. The unpredictable pace of future economic development in Poland, dependency on the EU-15 countries' decisions on access to their labour market and the poor quality of Polish statistics on international migration suggest that the uncertainty is higher than in the 18 EU/EEA countries studied in the UPE project. The standard deviation of net migration at the end of the forecast period was set at a level of $0.4 \%$ of the jump-off population. The corresponding $80 \%$ prediction interval is presented in Figure 9.

The future overall trend of net migration is very similar to that assumed by Eurostat in its projection, but the discrepancies still persist. They refer to the minimum level of net migration reached before the trend changes $(-59,000$ in the baseline Eurostat scenario compared to our point forecast of 88,500) and the pace of the increasing trend. The target levels of net migration in 2050 are very close to each other. The differences in the net migration level result to some extent from differences in the figure for the jump-off net migration, since the correction introduced by us is larger than that applied by Eurostat. However, since 2012 the base variant of the Eurostat projection is within the $80 \%$ prediction interval of our forecast. 
Figure 9 Net migration, past and forecasted values

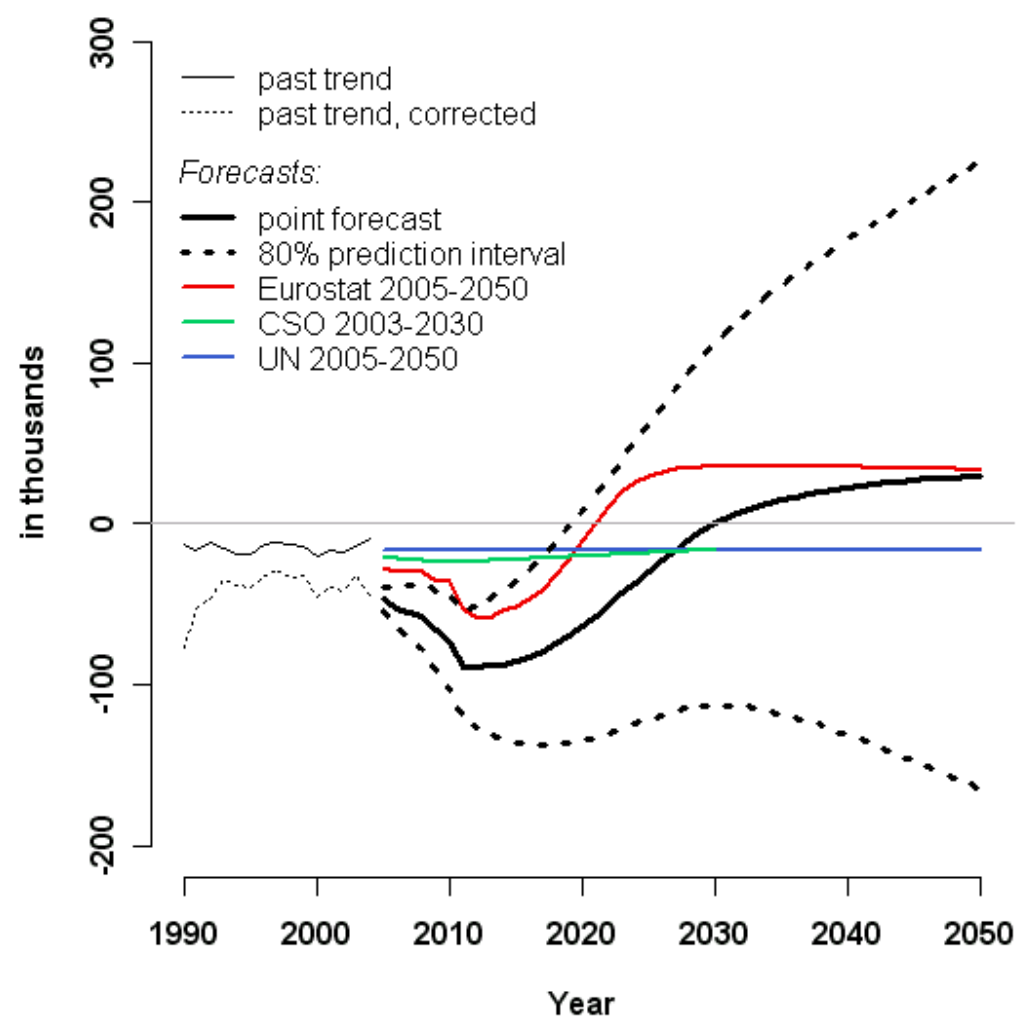

The UN and CSO consider only one variant of the future non-zero net migration pattern. Their assumptions are not comparable with the other two forecasts. The UN assumes constant net migration at the level of $-16,000$ and the CSO assumes a decline to $-24,000$ in 2010 and then a gradual increase to $-16,000$ in 2030 (projection lead time). These assumptions are highly questionable. Firstly, they are based on an underestimated registration number of net migrants and secondly, possible changes connected with Poland's entry into the EU are not taken into account.

\section{Forecast results}

\subsection{Total population}

Figure 10 contains the median and first and ninth deciles of the predictive distribution of the population of Poland until 2050. It is clear that the Polish population is most likely to decline from the current 38.2 million to 35.0 million in 2030 and to 30.9 million in 2050, as indicated by 
the median. This downward trend will be observed from the beginning of the forecast period. The $50 \%$ prediction interval places the Polish population between [33.0, 36.9] million in 2030 and [27.0, 34.8] million in 2050 . The $80 \%$ prediction interval is much wider and even allows for the possibility of the Polish population remaining at the current level or slightly increasing. More precisely, it ranges from the very low values of 31.6 to 38.7 in 2030 and from 23.8 million to 38.6 million in 2050.

Figure 10 Total population, past and predicted values

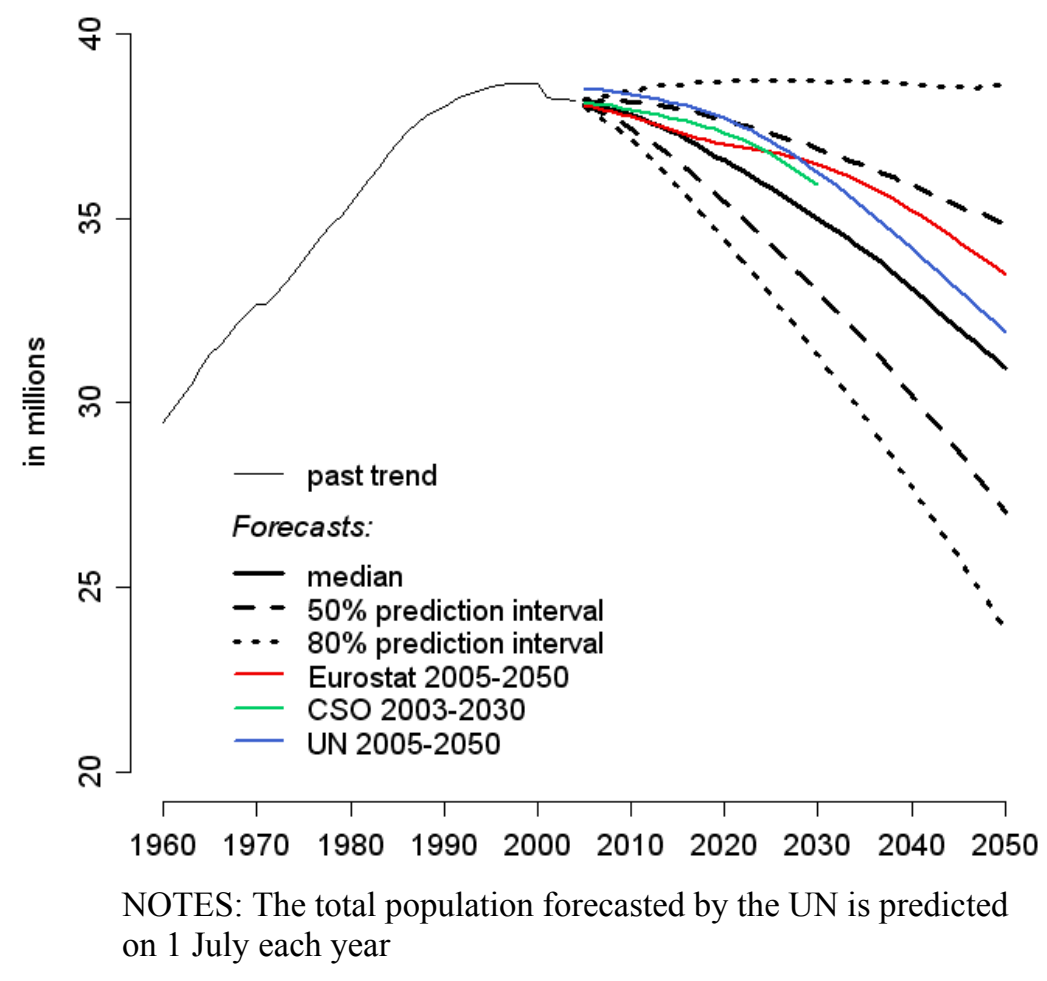

The medium forecasts of the total population by the CSO, UN, and Eurostat are nearly fully covered by the $50 \%$ prediction intervals obtained by us. However, they all give higher population numbers than our point forecast.

The CSO predicts the total Polish population to be 35.9 million in 2030, which is nearly one million higher than the median in our forecast. Since our point forecast on fertility places the TFR at a higher level than in the forecast by the CSO and since the assumptions on mortality for 2030 are quite similar, this difference results from different assumptions on migration. Indeed, in our point forecasts we definitely expect a much higher out-migration than does the CSO.

The base variant by Eurostat places the total population on a level similar to our point forecast in the first forecast years, until around 2018. Thenafter, it begins to predict higher values and in 2050 it yields 33.5 millions of inhabitants, i.e. 2.5 millions more than our point forecast. This 
difference is probably mainly a consequence of the fact that Eurostat's assumptions on fertility are much more optimistic than ours.

The UN medium scenario yields the highest differences in comparison to our point forecast in the first forecast years, until around 2030. This gap results probably from higher assumptions on fertility and lower out-migration. Thenafter the difference decreases but still the population is predicted to be 31.9 millions, that is by 0.7 million higher than in our point forecast.

\subsection{Age structure}

Along with the decline in its total population, Poland will face rapid population ageing. This process will not only be the result of low fertility and rising life expectancy but also of rolling demographic booms and busts in the past. As a consequence, the median age of the population will rise from 35.7 in 2004 to 46.4 in 2030 and 51.8 in 2050 (according to our point forecast).

Table $180 \%$ prediction interval for the median age of the population

\begin{tabular}{lccc}
\hline & $1^{\text {st }}$ decile & Median & $9^{\text {th }}$ decile \\
\hline 2004 & - & 35.7 & - \\
2030 & 48.2 & 46.4 & 44.6 \\
2050 & 56.8 & 51.8 & 46.9 \\
\hline
\end{tabular}

The change in the age structure of the population will be reflected in a gradual decline in the number of children aged 0-6 and at school age (aged 7-18) over the whole forecast period (with the exception of the years 2008-2011 in the case of the younger group). The working-age population (aged 19-64) will continuously decrease from 2011 onwards. Only in the case of the elderly (65+) will we observe a constant increase. A remarkable feature of these changes will be a significant rise in the number of oldest-old (80+) until the end of 2041. This has already been observed in EU-15 on a large scale during the last decades, but has not yet taken place to such an extent in the new member states. The general overview of these changes is graphed in the age pyramids (see Figure 11). The border of the dark grey area stands for the lower bound of the $80 \%$ prediction interval, whereas the border of the black area represents the upper bound. It is clear that uncertainty is highest in the young ages. Nevertheless, even if the future age structure of the population is as indicated by the ninth decile of the forecast, the age pyramid will remain of regressive shape. 
Figure 11 Future age structure of the population, median and $80 \%$ prediction intervals
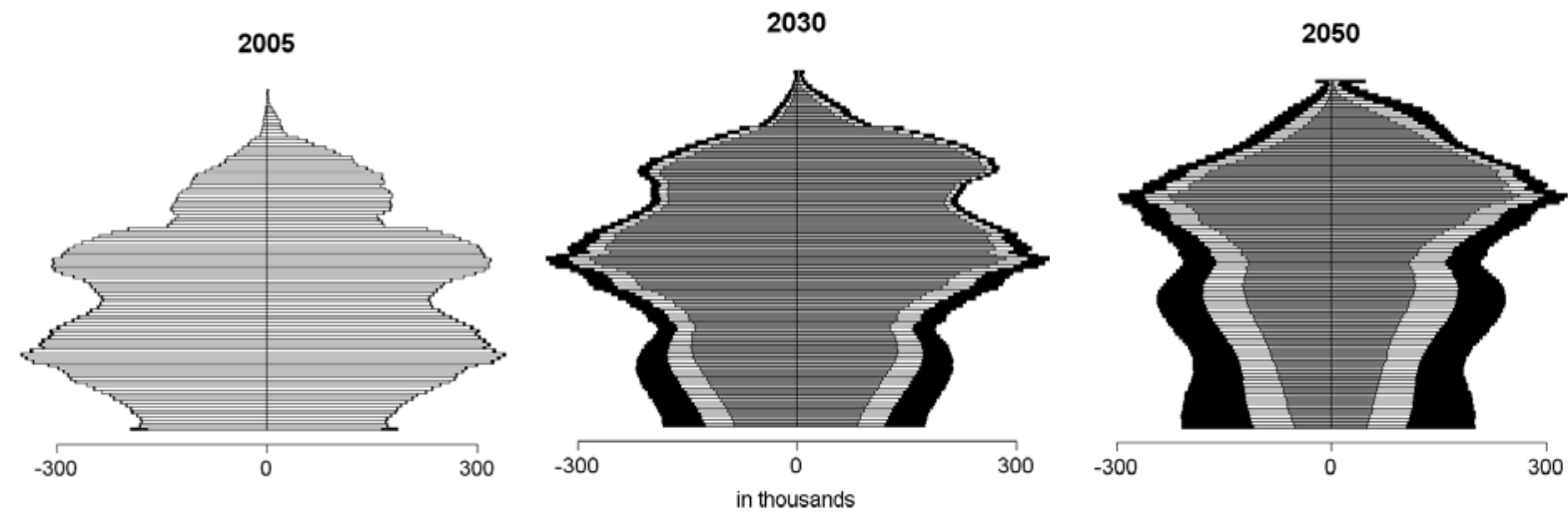

lower bound of the $80 \%$ prediction interval

$\checkmark$ median

upper bound of the $80 \%$ prediction interval

The process of population ageing is reflected also in a detailed analysis of population composition by age (see Figure 12). The main absolute changes in the population share refer to people aged 65-79 and at mobile productive age (19-44). The fraction of the former increases by 12 percentage points (from $10.6 \%$ up to $22.6 \%$ ) and that of the latter decreases by $11.6 \%$ percentage points (from $38.4 \%$ down to $26.8 \%$ ). The most substantial relative change in the share takes place in the oldest-old age group $(80+)$, which nearly triples. As a result, the fraction of the combined group of the elderly $(65+)$ increases from $13.3 \%$ to $32.3 \%$. Due to the assumed eventual rise in fertility rates, the decline in the share of children aged 0-6 is relatively small, lower than that for children at school age (7-18), in both absolute and relative terms.

Figure 12 Age structure of the population

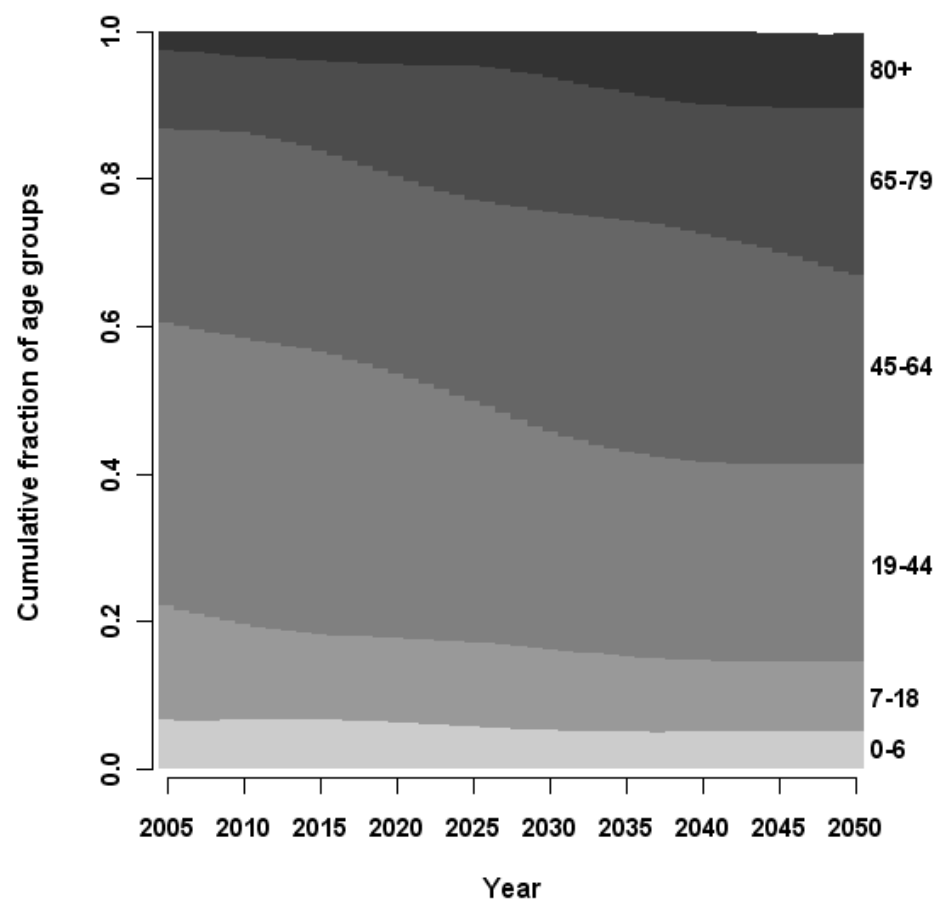


The pressure on the economy of population ageing can be described by the so-called old age dependency ratio (OADR). The OADR analysed in this study is defined as the size of population aged 65 and above, divided by the working age population (19-64). However, one needs to take into account that this measure does not reflect the exact burden placed by the dependant elderly on the working population due to variations in employment participation and eligibility to social benefits. The dynamics of the OADR presented in Figure 13 (median with an $80 \%$ prediction interval) reflects clearly a dramatic process of population ageing, which is connected with a substantial increase in the financial burden posed on the working age population.

Figure 13 Old-age dependency ratio (OADR), past and predicted values

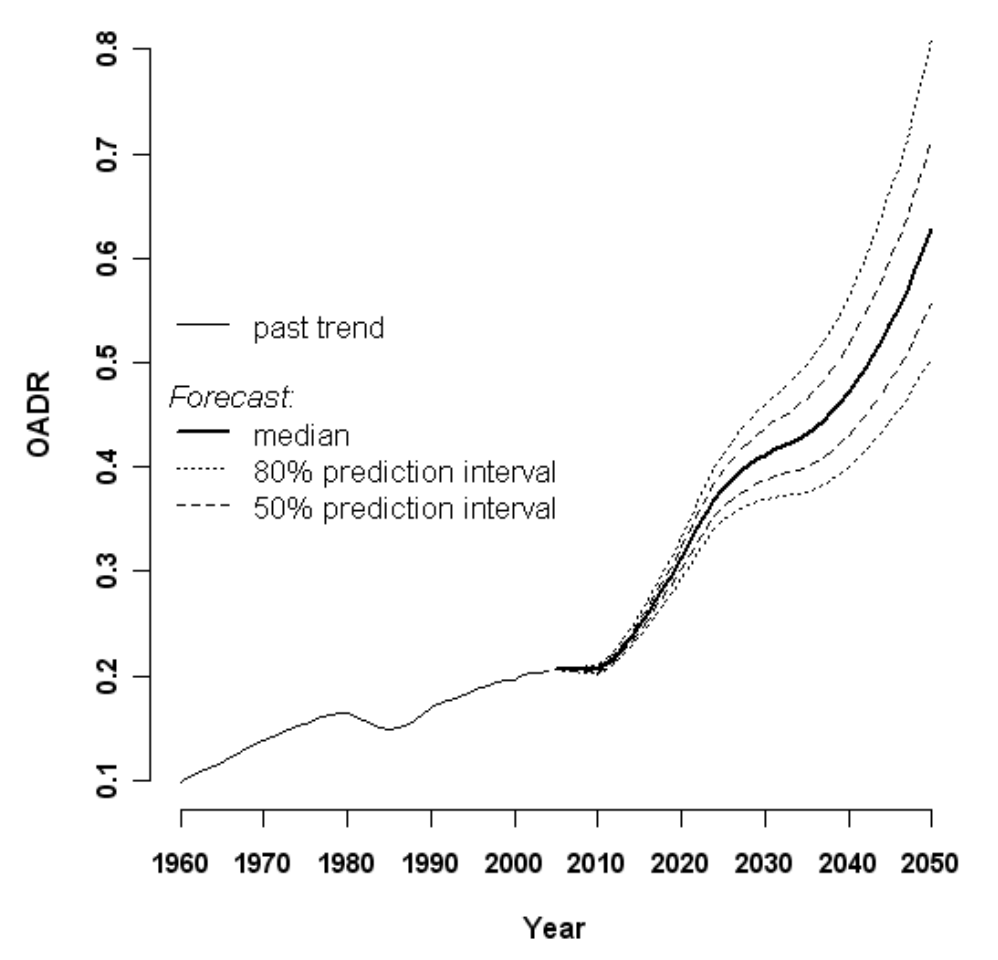

Over the forecast period, the OADR more than triples. According to our point forecast, it increases from $20 \%$ in the first years of the forecast to $41 \%$ in 2030 and $63 \%$ in 2050 . As the first decile for 2050 indicates (50\%), even given the favourable circumstances, the OADR will more than double until 2050. The pessimistic variant of the future demographic development will bring us to the level of $81 \%$. There is a probability of $10 \%$ that we will exceed this value in 2050 . 


\section{Conclusions}

No one can say with certainty what the demographic development in Poland of the future will look like, but compared to other existing forecasts for Poland prepared conventionally, we have quantified the uncertainty we should expect. The analysis of the historical forecast errors for Poland is limited, however, by the lack of long time-series data. Thus we had to rely on the experience of other countries. We have assumed that future uncertainty is at least as high as it was in the past for other European countries that possess appropriate data. This uncertainty is higher than usually believed by demographic forecasters. Even under these assumptions, we can be pretty sure that the population of Poland will decline in future and that a further advancement in population ageing is inevitable. This process will have severe implications on the financial conditions of the social security system and the state of public finance in this country. Policy makers should be aware of this process and take appropriate measures. In 1999, Poland reformed the non-agricultural pension system. The previous "pay-as-you-go" system has been gradually replaced by a new one, entirely based on individual retirement accounts (Góra, 2005). Nevertheless, disability, health care, agricultural pension, and the system of public finance still require major reforms (Wóycicka and Matysiak, 2004, 2005). An additional challenge is posed by the difficult labour market situation. The employment rates are exceptionally low, especially among the young and people at pre-retirement age. In sum, the study has revealed that considerable improvements need to be made to public finance in Poland, to its social security system as well as to the availability and quality of statistics in this country.

\section{Acknowledgements}

This forecast was prepared during our stay at the Max Planck Institute for Demographic Research as fellows in the European Doctoral School of Demography. We are very grateful to Juha Alho for his valuable teaching within the EDSD course on Modelling, simulation and forecasting. We also appreciate comments on an earlier version of this paper made by Marek Kupiszewski and Heiner Maier. Furthermore, we would like to thank Susann Backer for language editing. 


\section{Annex}

Table 1 Data sources for fertility indicators, Poland

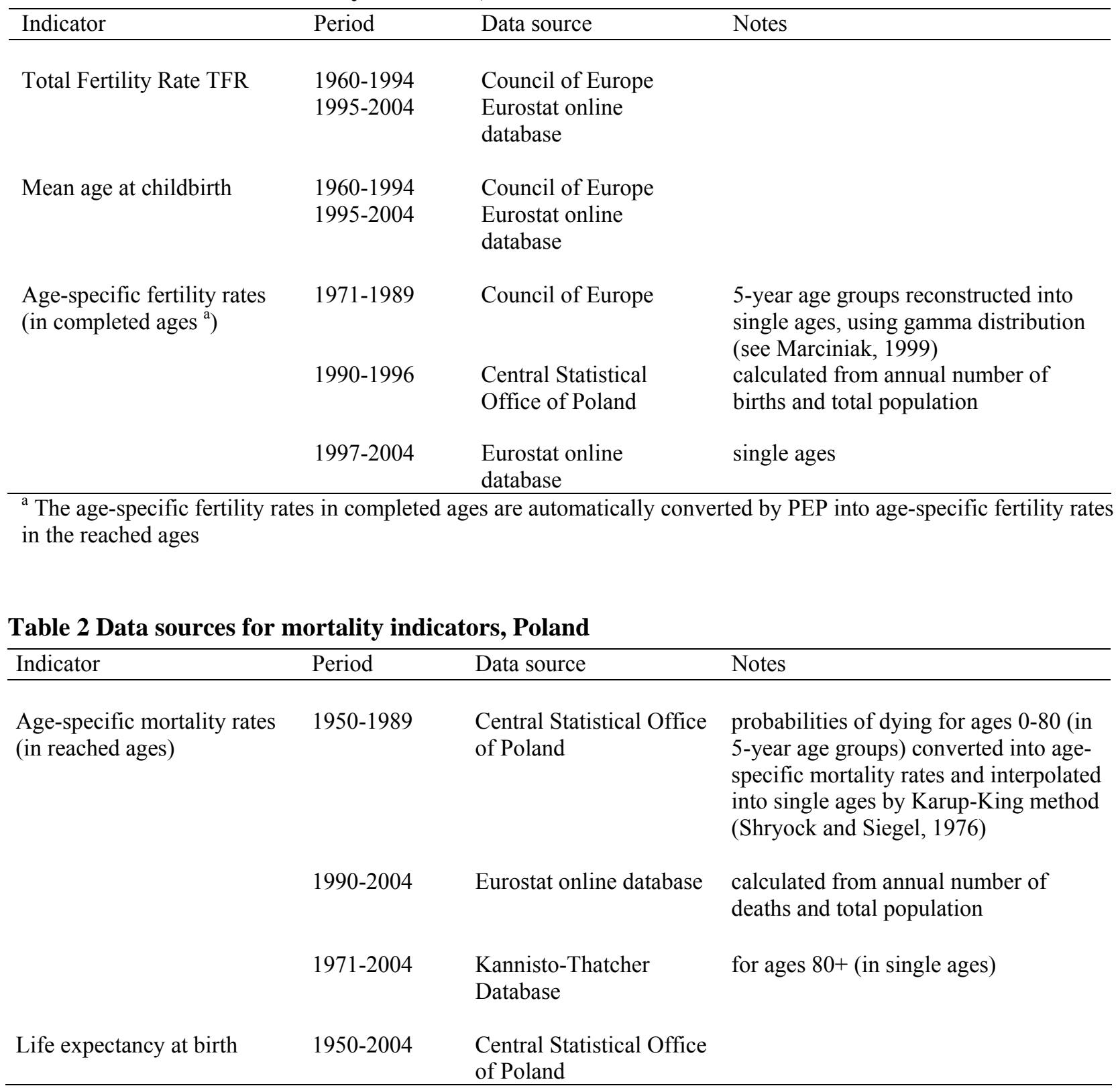




\section{References}

Alho, J., (1998). Stochastic Forecast of the Lithuanian Population 2001-2050. Research Report P98-1023-R. Joensuu: University of Joensuu, Department of Statistics.

Alho, J., and B. Spencer (2005). Statistical Demography and Forecasting. New York: Springer Science + Business Media.

Alho, J. (n.d.) PEP - Program for Error Propagation (tutorial). Retrieved April 4, 2006, from http://joyx.joensuu.fi/ ek/pep/userpep.htm

Bolesławski, L. (2004). Demographic projection of Poland 2003-2030. Warsaw: Central Statistical Office.

Central Statistical Office, Population Indicators Database, http://www.stat.gov.pl/dane_spolgosp/ludnosc/index.htm

Central Statistical Office (2003). Migracje zagraniczne ludności 2002. Warsaw: Central Statistical Office.

Council of Europe (2005). Recent demographic developments in Europe 2004. Strasbourg: Council of Europe Publishing.

Eurostat, online database (Population/Social conditions, Population, Population projections), http://europa.eu.int/comm/eurostat/

Eurostat (2005). EU25 population rises until 2025, then falls. Eurostat press release 448/2005 of 8 April 2005.

Góra, M. (2005). Pension expenditure as the part of GDP: Social security vs. economic growth. Discussion Paper No.265. Project on Intergenerational Equity. Hitotsubashi: Institute of Economic Research, Hitotsubashi University.

Kannisto-Thatcher Database on Old Age Mortality (n.d.). Max Planck Institute for Demographic Research. Retrieved April 4, 2006, from http://www.demogr.mpg.de/

Keilman, N., D. Q. Pham, and A. Hetland (2002). Why population forecasts should be probabilistic - illustrated by the case of Norway. Demographic Research, 6(15), 410-453.

Keilman, N., and D. Q. Pham (2004). Empirical errors and predicted errors in fertility, mortality and migration forecast in the European Economic Area, Discussion Paper No 386, Statistics Norway, Social and Demographic Research.

Kotowska, I. E., A. Matysiak, M. Muszyńska, and A. Abramowska (2005). Work and Parenthood. Comparative Report and Summary Policy Implications. Research report for the European Commission prepared within the DIALOG Project, Work package: Work and Parenthood.

Kupiszewska, D., and B. Nowok (2005). Comparability of statistics on international migration flows in the European Union. Warsaw: CEFMR Working Paper 7/2005. 
Marciniak, G. (1999). Symulacje zmian wzorca płodności do 2005r. Studia Demograficzne, 2(136).

Muszyńska, M. (2005). Structural and cultural determinants of fertility in Europe. PhD thesis. Warsaw: Warsaw School of Economics, Institute of Statistics and Demography.

Nowok, B. (2005). Evolution of international migration statistics in selected Central European countries: collection methods, concepts and international comparability. Warsaw: CEFMR Working Paper 8/2005.

Oeppen, J., and J. W. Vaupel (2002). Broken limits to life expectancy. Science, 296(5570), 10291031.

Olshansky, S. J., B. A. Carnes, and C. Cassel (1990). In search of Methuselah: Estimating the upper limits to human longevity. Science, 250(4981), 634-640.

Shryock, H. S., and J. S. Siegel (1976). The methods and materials of demography. New York: Academic Press.

UPE (2004). A forecast of the population of Europe 2004-2050, http://www.stat.fi/tup/euupe/

United Nations and Eurostat (1998). Recommendations for the 2000 censuses of population and housing in the ECE region. Statistical Standards and Studies No. 49. New York and Geneva: United Nations.

United Nations (2004).World Population Prospects: The 2004 Revision Database, http://esa.un.org/unpp/

Vaupel, J.W. (2005). The biodemography of aging. In L. W. Waite (Ed.), Aging, health, and public policy: demographic and economic perspectives (pp.48-62). New York: Population Council. (Supplement: Population and Development Review, 30,2004).

Wóycicka, I., and A. Matysiak (2005). Polityka społeczna na rzecz zatrudnienia. In Biała Księga 2005 (pp. 110-129). Gdańsk-Warszawa: Polskie Forum Strategii Lizbońskiej and Instytut Badań nad Gospodarką Rynkową.

Wóycicka, I., and A. Matysiak (2004). Czy Polacy muszą zrezygnować z wcześniejszych emerytur? In I. Wóycicka (Ed.), Później na emeryturę? Niebieska Księga 16, (pp.52-69). Gdańsk: Polskie Forum Strategii Lizbońskiej and Instytut Badań nad Gospodarką Rynkowa. 